\title{
Characterization of putative drug resistant biomarkers in Plasmodium falciparum isolated from Ghanaian blood donors
}

Enoch Aninagyei ${ }^{1 *}$ D, Kwabena Obeng Duedu', Tanko Rufai ${ }^{2,3}$, Comfort Dede Tetteh ${ }^{4}$, Margaretta Gloria Chandi ${ }^{5}$, Paulina Ampomah ${ }^{6}$ and Desmond Omane Acheampong ${ }^{6,7^{*}}$

\begin{abstract}
Background: Plasmodium falciparum parasites, which could harbour anti-malaria drug resistance genes, are commonly detected in blood donors in malaria-endemic areas. Notwithstanding, anti-malaria drug resistant biomarkers have not been characterized in blood donors with asymptomatic $P$. falciparum infection.

Methods: A total of 771 blood donors were selected from five districts in the Greater Accra Region, Ghana. Each donor sample was screened with malaria rapid diagnostic test (RDT) kit and parasitaemia quantified microscopically. Dried blood spots from malaria positive samples were genotyped for $P$. falciparum chloroquine resistance transporter (Pfcrt), P. falciparum multi-drug resistance (Pfmdr1), P. falciparum dihydropteroate-synthetase (Pfdhps), P. falciparum dihydrofolate-reductase (Pfdhfr) and Kelch 13 propeller domain on chromosome 13 (Kelch 13) genes.

Results: Of the 771 blood donors, 91 (11.8\%) were positive by RDT. Analysis of sequence reads indicated successful genotyping of Pfcrt, Pfmdr1, Pfdhfr, Pfdhps and Kelch 13 genes in 84.6, 81.3, 86.8, 86.9 and 92.3\% of the isolates respectively. Overall, 21 different mutant haplotypes were identified in 69 isolates (75.8\%). In Pfcrt, CVIET haplotype was observed in $11.6 \%$ samples while in Pfmdr1, triple mutation (resulting in YFN haplotype) was detected in $8.1 \%$ of isolates. In Pfdhfr gene, triple mutation resulting in IRNI haplotype and in Pfdhps gene, quintuple mutation resulting in AGESS haplotype was identified in $17.7 \%$ parasite isolates. Finally, five non-synonymous Kelch 13 alleles were detected; C580Y (3.6\%), P615L (4.8\%), A578S (4.8\%), I543V (2.4\%) and A676S (1.2\%) were detected.

Conclusion: Results obtained in this study indicated various frequencies of mutant alleles in Pfcrt, Pfmdr1, Pfdhfr, Pfdhps and Kelch 13 genes from P. falciparum infected blood donors. These alleles could reduce the efficacy of standard malaria treatment in transfusion-transmitted malaria cases. Incorporating malaria screening into donor screening protocol to defer infected donors is therefore recommended.
\end{abstract}

Keywords: Plasmodium falciparum, Blood donors, Putative drug resistant biomarkers, Mutant haplotypes, Ghana

\footnotetext{
*Correspondence: eaninagyei@uhas.edu.gh; dacheampong@ucc.edu.gh

${ }^{1}$ Department of Biomedical Sciences, School of Basic and Biomedical

Sciences, University of Health and Allied Sciences, Ho, Volta Region, Ghana

${ }^{6}$ School of Allied Health Sciences, Department of Biomedical Sciences,

School of Allied Health Sciences, College of Health and Allied Science,

University of Cape Coast, Cape Coast, Ghana

Full list of author information is available at the end of the article
}

(c) The Author(s). 2020 Open Access This article is licensed under a Creative Commons Attribution 4.0 International License, which permits use, sharing, adaptation, distribution and reproduction in any medium or format, as long as you give appropriate credit to the original author(s) and the source, provide a link to the Creative Commons licence, and indicate if changes were made. The images or other third party material in this article are included in the article's Creative Commons licence, unless indicated otherwise in a credit line to the material. If material is not included in the article's Creative Commons licence and your intended use is not permitted by statutory regulation or exceeds the permitted use, you will need to obtain permission directly from the copyright holder. To view a copy of this licence, visit http://creativecommons.org/licenses/by/4.0/ The Creative Commons Public Domain Dedication waiver (http://creativecommons.org/publicdomain/zero/1.0/) applies to the data made available in this article, unless otherwise stated in a credit line to the data. 


\section{Background}

Lack of sensitive screening tools for detecting asymptomatic malaria in blood donors is believed to have contributed significantly to the underestimation of the global burden of transfusion-transmitted malaria (TTM) [1]. In Ghana, the prevalence of malaria among blood donors have been reported to be between 8 and $13.7 \%$ by rapid diagnostic testing (RDT) and 3-4.7\% by microscopy [24]. In 2016, cases of TTM were reported from different provinces in Iran [5] and in Ghana [2]. In blood recipients with no or reduced immunity to malaria, TTM can be fatal, if infections are not detected and treated quickly [6]. The parasite species most frequently associated with transfusion malaria are Plasmodium falciparum, P. malariae and P. vivax $[7,8]$. Blood donors with semi-immunity could harbor low levels of the Plasmodium parasites, which are mostly below the detection threshold of currently available assays. This will cause malaria parasites to persist for several years in infected blood recipients [7, 9]. During storage, malaria parasites have been found to survive in donated blood at temperatures between $2{ }^{\circ} \mathrm{C}$ and $6{ }^{\circ} \mathrm{C}$ for 3 weeks, with the estimated inoculum in transfusions from one to 10 parasites per donation [10, 11]. Transfusing one malaria parasite per microliter of infected blood, converts to about 500,000 infected red cells in one unit of blood [2]. Most reported cases of TTM were either through whole blood or red blood cell concentrates, with a few cases of TTM occurring after platelets and leukocytes transfusions [12].

Genetic diversity of $P$. falciparum has been attributed partly to its ability to evade host immune system [13] and adapt to anti-malarials [14]. Alleles of P. falciparum chloroquine resistance transporter gene (Pfcrt) have been associated with chloroquine resistance in $P$. falciparum [15]. P. falciparum multi-drug resistance (Pfmdr) gene is also associated with both chloroquine and amodiaquine resistance [16]. Mutations in P. falciparum dihydropteroate-synthetase (Pfdhps) gene confer resistance to sulfadoxine [17] while $P$. falciparum dihydrofolate-reductase (Pfdhfr) gene alleles are also associated with resistance to pyrimethamine [18]. High prevalence of mutations in Pfdhfr and Pfdhps will undermine the prophylactic effect of sulphadoxine-pyrimethamine in pregnant women and immigrants visiting malaria endemic regions from non-endemic countries [19]. Finally, non-synonymous single nucleotide polymorphisms in the Kelch 13 propeller domain on chromosome 13 (Kelch 13) were found to be strongly associated with resistance to artemisinin derivatives [20].

Artemisinin-based combination therapies (ACTs) have contributed to the substantial decline in malaria burden. However, the efficacy of ACTs is threatened by the emergence of artemisinin resistance in $P$. falciparum that led to treatment failure of ACTs in South-East
Asian countries namely, Thailand, Cambodia, Vietnam and Myanmar [21].

In previous studies in Ghana, high frequencies of mutation in Pfcrt, Pfmdr1, Pfdhfr and Pfdhps were identified in $P$. falciparum infected children aged 4-15 years [22, 23]. However, such study is yet to done in Ghanaian adults and for that matter, blood donors. Hence, this study was designed to determine the magnitude of the risk associated with the transmission of these putative anti-malaria drug resistant biomarkers through blood transfusion.

\section{Methods}

\section{Study design}

This cross-sectional study involved consented blood donors that were randomly recruited from five districts in the Greater Accra region of Ghana. The districts were Ada East, Ashaiman, Accra Metropolis, Ga South and Ga West (Fig. 1). For each blood donor, $5 \mathrm{~mL}$ of CPDA1 anticoagulated blood was collected, kept on ice packs $\left(\sim 6-10^{\circ} \mathrm{C}\right)$ and sent to Ga West Municipal Hospital Blood Bank, Amasaman-Accra for analysis. Blood donors were recruited from November 2017 to August 2018. Each blood sample was screened for transfusion transmissible infections (TTIs) (HIV I\&II, hepatitis B, hepatitis $\mathrm{C}$ and syphilis) using enzyme immunoassays as described previously [24]. All TTIs infected donor blood units were excluded from further analysis. The TTIsnegative donor blood units were then screened for malaria parasites. Subsequently, four dried blood spots were prepared on filter paper for all malaria infected donor blood units, and sent to Malaria Genome Laboratory, Wellcome Sanger Institute, Hinxton-United Kingdom for genotyping by sequencing for putative anti-malaria drug resistant biomarkers.

\section{Sample size determination}

Minimum number of prospective blood donors recruited for this study was determined using the Cochrane's formula: $n=\mathrm{z}^{2} \mathrm{p}(1-\mathrm{p}) / \mathrm{d}^{2}$, where $n=$ sample size, $\mathrm{p}=$ proportion of blood donors infected with $P$. falciparum, $1-\mathrm{p}=$ proportion of blood donors not infected with $P$. falciparum, $z=$ confidence level at 95\% (standard value of 1.96), $d=$ margin of error at $5 \%$ (standard value of 0.05 ). Prevalence of $P$. falciparum in blood donors was determined in the Volta Region, the closest region to Greater Accra Region, be $10.0 \%$ [3]. Based on these values, the sample size was calculated to be 139 prospective blood donors.

\section{Donor selection}

Blood donors were selected according to Medical History Guide for Donor Selection protocol [25]. Prospective donors included in the study were individuals aged 


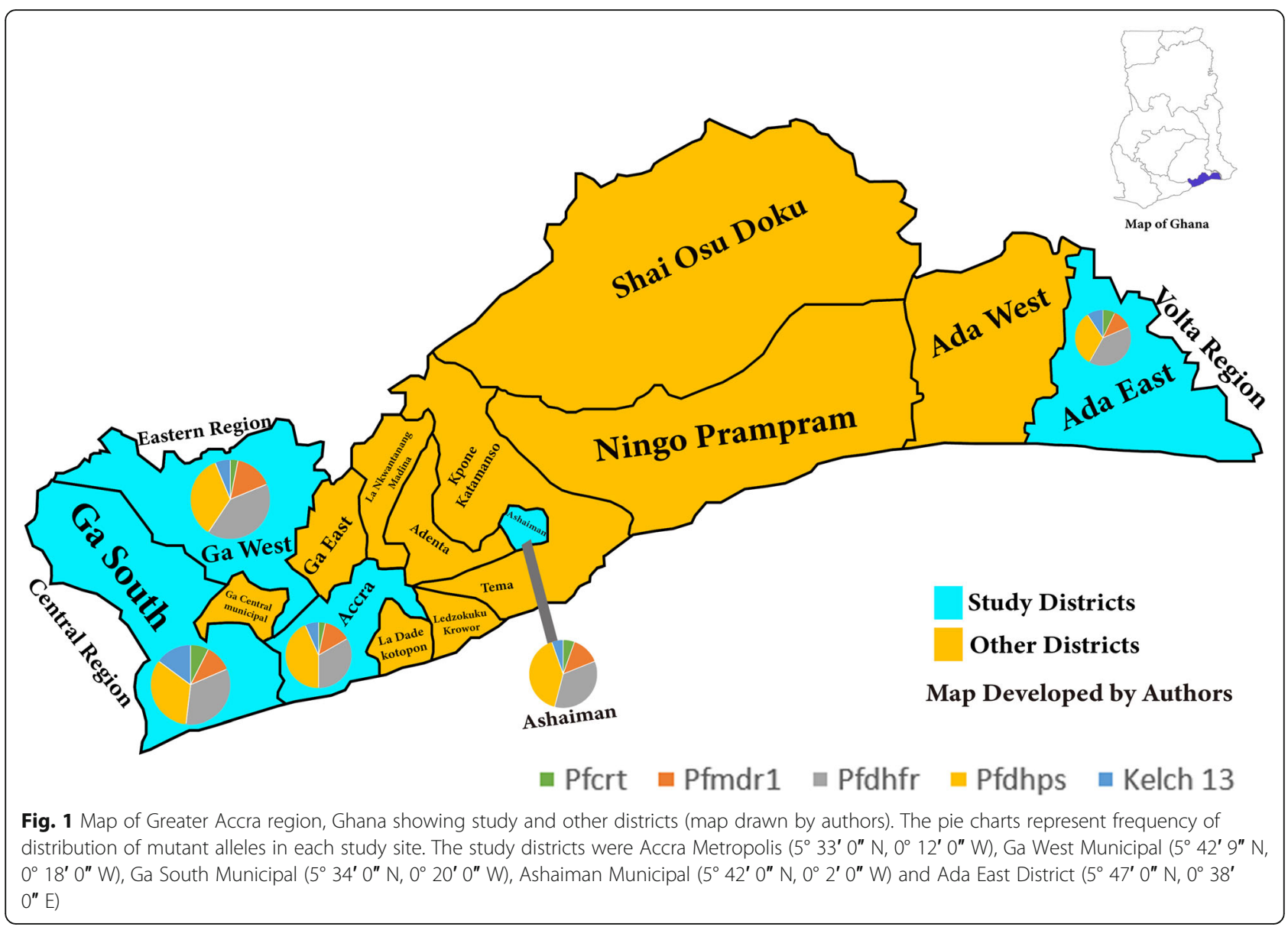

between 18 and 59 years that had resided in their respective study districts for not less than $1 \mathrm{y}$. Consented blood donors were selected for this study by selecting any other donor that came to donate blood. This was done by sampling either all even or all odd numbered blood donors depending on the random choice for the donation day. Prospective blood donors were screened using National Blood Service, Ghana's self-exclusive questionnaire. Additionally, donors' malaria history was taken. In this study, donor selection and donor blood collection was done in collaboration with National Blood Service Ghana.

\section{Donor phlebotomy and study specimen collection}

Donor phlebotomy was done according to Guidelines on drawing blood published by World Health Organization [26] with slight modification. Briefly, a large, firm vein, preferably in the antecubital fossa was selected. A tourniquet was applied to make the vein more prominent. Donor was made to squeeze the fist intermittently. Once the vein was selected, the skin site was disinfected using $70 \%$ isopropyl alcohol. The area was allowed to dry completely. Venipuncture was performed using a smooth, clean entry with 16-gauge needle which was attached to the blood collection bag. As soon as blood flow was established, the donor was asked to open and close the fist slowly every 10-12 s during collection whilst the tourniquet was removed. The donor was closely monitored during bleeding. About every $30 \mathrm{~s}$ during the donation, the collected blood was gently mixed with the anticoagulant using mechanical mixer. After adequate blood has been collected, the needle was removed, injection sites dressed, the needle was severed from the collected tube, blood labeled and kept on ice pack. Approximately $5 \mathrm{~mL}$ of anticoagulated blood sample was collected for laboratory testing.

\section{Study variables}

The study variables were, completed age in years of blood donor, gender, number of successful previous blood donations, history of clinical malaria, present body temperature, malaria testing outcomes and frequencies of putative anti-malaria drug resistant alleles. Questionnaires were used to obtain the age, gender, number of successful previous donations and history of clinical malaria. However, body temperature was determined on the day of blood donation using digital infra-red noncontact thermometers (Kinlee, Guangdong). Malaria 
screening was performed with SD Bioline rapid diagnostic kit whilst putative anti-malaria drug resistant alleles were determined using DNA sequencing approach.

\section{Laboratory procedures \\ Screening for malaria parasites and parasitaemia determination}

Donor blood malaria screening was done with the SD Bioline PfHRP-2/pLDH rapid diagnostic test kit (Gyeonggi-do, Republic of Korea). Malaria parasitaemia was determined in PfHRP2/pLDH positive donor units that satisfied the inclusion criteria. Malaria parasitaemia was quantified according to WHO protocol [27]. Quantification was done by dividing the number of asexual parasites per at least 200 leukocytes and multiplied by average WBC count of 8000 cells/ $\mu \mathrm{L}$ of blood.

\section{Preparation of dry blood spots (DBS)}

Dried blood spots (DBS) were prepared using approx. $50 \mu \mathrm{L}$ of anticoagulated whole blood. In all, four blood spots were prepared (two blood spots measuring approximately $15 \mathrm{~mm}$ in diameter on one filter paper). The blood spots were completely dried at room temperature.

\section{Plasmodium falciparum genomic DNA extraction}

P. falciparum DNA was extracted from dried blood spots (DBS) using QIAamp DNA Investigator Kit (Qiagen, California, United States) following kit manufacturer's instructions. At least $5 \mathrm{ng}$ of DNA was used as template for sequencing.

\section{Plasmodium falciparum primers and probes used in this study}

Primers used to identify and genotype $P$. falciparum genome in this study were developed by Oyola et al. [28] and previously used by Aninagyei et al. [24] to detect asymptomatic $P$. falciparum infections in blood donors. The primers were designed to bind to the $P$. falciparum genome reference genome, $P$. falciparum 3D7 genome.

\section{P. falciparum genome sequencing and analysis}

The detailed methodology for detecting and sequencing $P$. falciparum genome using selective whole genome amplification (sWGA) has been published by Aninagyei et al [24]. The sWGA reaction was performed using DNA template ( $\geq 5 \mathrm{ng}$ ). The reaction mix was made up of the following: template DNA, $1 \times$ bovine serum albumin, $1 \mathrm{mM}$ dNTPs, $2.5 \mu \mathrm{M}$ of each amplification primer, $1 \times$ Phi29 reaction buffer and 30 units of Phi29 polymerase enzyme (New England Biolabs). Isothermal amplification conditions were used $\left(35^{\circ} \mathrm{C}\right.$ for $5 \mathrm{~min}, 34^{\circ} \mathrm{C}$ for $10 \mathrm{~min}, 33^{\circ} \mathrm{C}$ for $15 \mathrm{~min}, 32^{\circ} \mathrm{C}$ for $20 \mathrm{~min}, 31^{\circ} \mathrm{C}$ for 30 min, $30^{\circ} \mathrm{C}$ for $16 \mathrm{~h}$ prior to denaturing Phi29 polymerase enzyme $65^{\circ} \mathrm{C}$. Ampure XP cleaned amplicons washed with $200 \mu \mathrm{L}$ of $80 \%$ ethanol and eluted with elution buffer. Using the NEBNext ${ }^{\circ}$ Ultra $^{\text {Tx }}$ DNA library preparation kit (New England Biolabs), DNA libraries were prepared prior to sequencing on Illumina HiSeq 2500 DNA Sequencer. After sequencing, demultiplexing and fastq data files were generated automatically. Low quality reads were trimmed (Bioedit v7.2) and each dataset analysed independently by mapping sequence reads to the $P$. falciparum 3D7 reference genome using Burrows-Wheeler Aligner. Allelic analysis was done for Pfcrt, Pfdhfr, Pfdhps, Pfmdr1 and Kelch13 genes.

\section{Data processing and statistical analysis}

All percentages were computed by simple proportions using Microsoft excel 2016. Association of malaria parasitaemia to total number of mutant alleles were done with Pearson correlation test while association between mutant alleles and demographic determinants were determined by Chi square test. All analyses were done with SPSS Version 24 (Chicago, IL, USA).

\section{Results}

Outcome of the donor recruitment and screening for asymptomatic $P$. falciparum

At the end of the donor recruitment period, the National Blood Service, Ghana registered 2271 prospective blood donors. Of this total, 1987 (87.5\%) were eligible to donate blood based on the self-exclusion questions and haemoglobin concentrations levels. Random sampling method selected 838 prospective donors but 67 (8.0\%) declined to participate in this study while consent was granted by 771 (92.0\%) blood donors (Fig. 2). All blood donors were negative for transfusion-transmitted infections (HIV 1\&2, syphilis, hepatitis B and C).

\section{Description and frequency of blood donations of the malaria infected blood donors}

This study recruited 771 consented blood donors (aged 19-59 years). Of this number 91 blood donors representing $11.8 \%$ were found to be asymptomatically infected with $P$. falciparum parasite. The district with the most infected blood donors was Ada East district (18.1\%) whilst Ga South municipal (9.2\%) reported the least infected blood donors. Most of the infected blood donors were between 31 and 40 years and majority of them were males. More than half of the infected donors (64.8\%) were donating for the first time whilst the rest had donated more than once. Eleven of the infected blood donors (12.1\%) have had clinical malaria within the past year. Donor malaria parasitaemia did not associate past malaria episode within past year $\left(x^{2}=3.6, p=0.059\right)$, number of blood donations $\left(x^{2}=8.2, p=0.08\right)$ and gen$\operatorname{der}\left(x^{2}=2.3, p=0.13\right)$. However, donor age associated with infection status $\left(x^{2}=18.8, p=0.003\right)$ with higher 


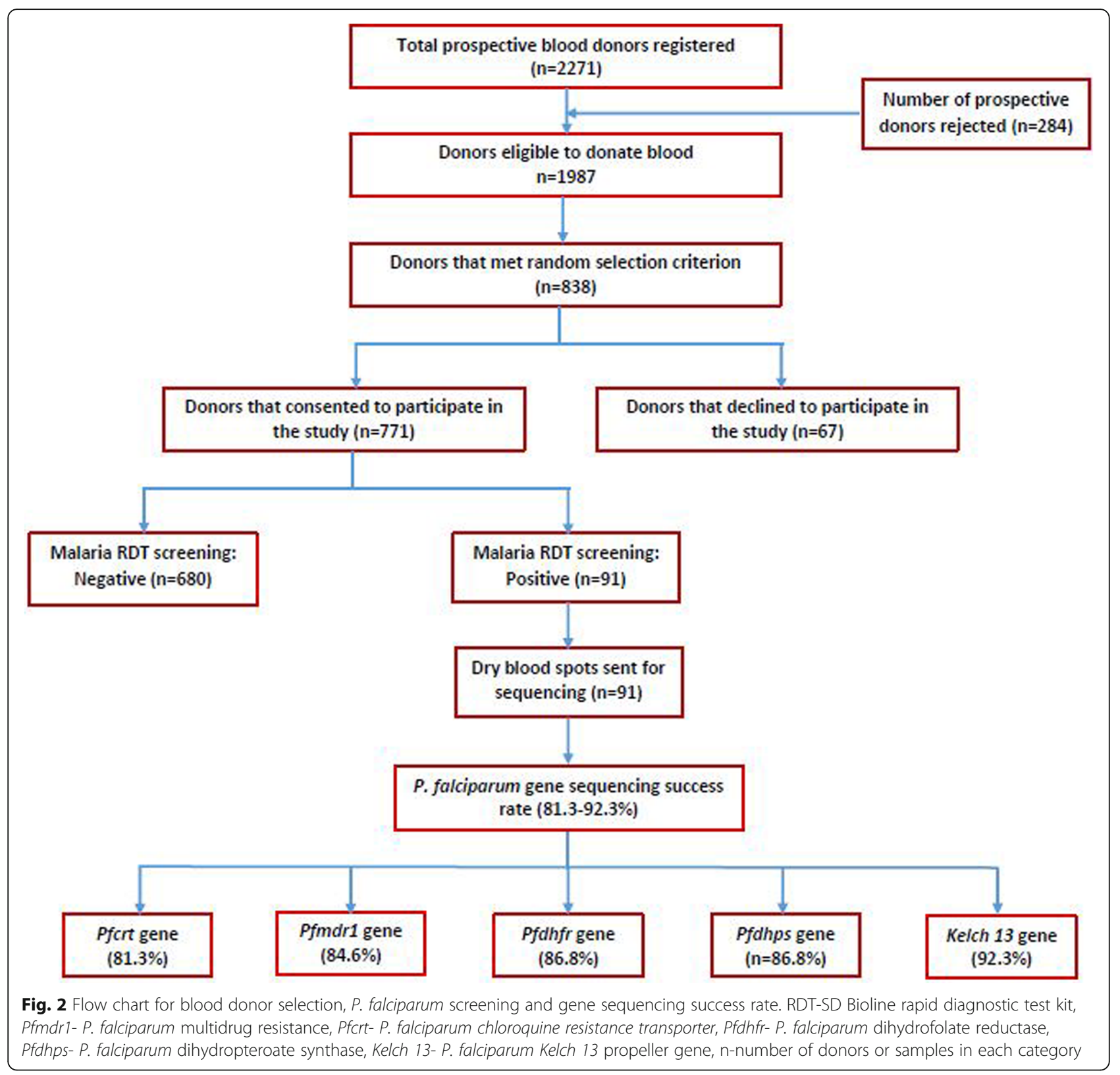

infections observed in 31-40-year range. Meanwhile, the overall mean body temperature of the infected donors was $36.9 \pm 0.56^{\circ} \mathrm{C}$ (Table 1$)$.

\section{$P$. falciparum genotype by sequencing success rate}

The genotyping success rate for $P$. falciparum chloroquine resistance transporter (Pfcrt), P. falciparum multidrug resistance-1 (Pfmdr1), P. falciparum dihydrofolate reductase $(P f d h f r), P$. falciparum dihydropteroate synthase (Pfdhps) and P. falciparum Kelch 13 propeller gene (Kelch 13) genes are presented in Table 2. Of the 91 samples submitted for sequencing, the success rate ranged from $81.3 \%$ for Pfmdr1 to $92.3 \%$ for Kelch 13. It was observed that sequencing was not successful for parasite count of less than 382 parasites/ $\mu \mathrm{L}$ of blood $(n=7)$.

Characterization of mutant haplotype identified in Pfcrt, Pfmdr1, Pfdhfr, Pfdhps and Kelch 13 genes

In $P f$ crt gene, mutations were only observed at amino acid positions 74, 75 and 76 but not at positions 72 and 73. At positions 74, 75 and 76, isoleucine, glutamic acid and threonine replaced methionine, asparagine and lysine respectively. The resultant haplotype was CVIET. These mutations occurred in only nine parasite isolates. In Pfmdr1 gene, four different single nucleotide polymorphisms (SNPs) were identified. These SNPs resulted in different amino acids at positions 86 (tyrosine), 184 
Table 1 District-wise demographic and clinical variables of the malaria infected blood donors

\begin{tabular}{|c|c|c|c|c|c|c|}
\hline $\begin{array}{l}\text { Demographic } \\
\text { variables }\end{array}$ & $\begin{array}{l}\text { Total } n \\
(\%)\end{array}$ & $\begin{array}{l}\text { Ada East District } \\
(n=149)\end{array}$ & $\begin{array}{l}\text { Ashaiman Municipal } \\
(n=164)\end{array}$ & $\begin{array}{l}\text { Accra Metropolis } \\
(n=155)\end{array}$ & $\begin{array}{l}\text { Ga South Municipal } \\
(n=140)\end{array}$ & $\begin{array}{l}\text { Ga West Municipa } \\
(n=163)\end{array}$ \\
\hline Malaria rapid test & $91(11.8)$ & $27(18.1 \%)$ & $19(11.6 \%)$ & $15(9.7 \%)$ & $13(9.2 \%)$ & $17(10.4 \%)$ \\
\hline \multicolumn{7}{|c|}{ Age in complete years* } \\
\hline $18-30(n=171)$ & $18(19.7)$ & $5(18.5 \%)$ & $3(15.7 \%)$ & $4(26.7 \%)$ & $2(15.4 \%)$ & $4(23.5 \%)$ \\
\hline $31-40(n=268)$ & $41(45.0)$ & $12(44.4 \%)$ & $9(47.4 \%)$ & 7 (46.7\%) & $5(38.4 \%)$ & $8(47.0 \%)$ \\
\hline $41-50(n=238)$ & $23(25.3)$ & 7 (25.9\%) & $5(26.3 \%)$ & $3(20.0 \%)$ & $5(38.4 \%)$ & $3(17.6 \%)$ \\
\hline $51-59(n=94)$ & $9(9.9)$ & $3(11.1 \%)$ & $2(10.5 \%)$ & $1(6.7 \%)$ & $1(7.7 \%)$ & $2(11.7 \%)$ \\
\hline \multicolumn{7}{|l|}{ Gender } \\
\hline Males $(n=609)$ & $78(85.7)$ & $22(81.4 \%)$ & $16(84.2 \%)$ & $13(86.7 \%)$ & $12(92.3 \%)$ & 15 (88.2\%) \\
\hline $\begin{array}{l}\text { Females }(n= \\
162)\end{array}$ & $13(14.3)$ & $5(18.5 \%)$ & $3(15.8 \%)$ & $2(13.3 \%)$ & $1(7.7 \%)$ & $2(11.8 \%)$ \\
\hline \multicolumn{7}{|c|}{ Number of blood donations } \\
\hline $1(n=395)$ & $59(64.8)$ & $17(62.9 \%)$ & $13(68.4 \%)$ & $10(66.7 \%)$ & $8(61.5 \%)$ & $11(64.7 \%)$ \\
\hline $2(n=124)$ & $14(15.4)$ & $5(18.5 \%)$ & $2(10.5 \%)$ & $2(13.3 \%)$ & $1(7.7 \%)$ & $4(23.5 \%)$ \\
\hline $3(n=111)$ & $8(8.8)$ & $2(7.4 \%)$ & $2(10.5 \%)$ & $1(6.7 \%)$ & $2(15.4 \%)$ & $1(5.9 \%)$ \\
\hline $4(n=89)$ & $8(8.8)$ & $2(7.4 \%)$ & $1(5.3 \%)$ & $2(13.3 \%)$ & $2(15.4 \%)$ & $1(5.9 \%)$ \\
\hline$>5(n=54)$ & $2(2.2)$ & $1(3.7 \%)$ & $1(5.3 \%)$ & $0(0.0 \%)$ & $0(0.0 \%)$ & $0(0.0 \%)$ \\
\hline \multicolumn{7}{|c|}{ At least one episode of malaria within the past 1 year } \\
\hline Yes $(n=79)$ & $11(12.1)$ & $5(18.5 \%)$ & $2(10.5 \%)$ & $0(0.0 \%)$ & $3(23.1 \%)$ & $1(5.9 \%)$ \\
\hline No $(n=692)$ & $80(87.9)$ & $22(81.5 \%)$ & $17(89.5 \%)$ & $15(100 \%)$ & $10(76.9 \%)$ & $16(94.1 \%)$ \\
\hline \multicolumn{7}{|c|}{ Body temperature $\left({ }^{\circ} \mathrm{C}\right)$} \\
\hline Mean \pm standard & deviation & $36.7 \pm 0.77$ & $37.1 \pm 0.12$ & $36.88 \pm 0.51$ & $36.8 \pm 0.68$ & $37.0 \pm 0.72$ \\
\hline $95 \% \mathrm{Cl}$ & & $36.1-37.40$ & $36.8-37.4$ & $36.4-37.3$ & $36.1-37.6$ & $36.3-37.6$ \\
\hline
\end{tabular}

* Significant association with donor parasitaemia

(phenylalanine) and 1246 (tyrosine) compared to the wild type. These nucleotide polymorphisms resulted in NFD, NYY, NFY and YFN haplotypes. The wild type haplotype of Pfdhfr gene is asparagine, cysteine, serine, isoleucine (NCSI) at 51, 59, 108 and 164 respective amino acid positions. Sequencing analysis indicated two different single mutations in the $P f d h f r$ gene. They were NRSI and NCNI where cysteine at position 59 mutated to arginine in the former and serine at position 108 changed to asparagine in the latter. Again, two double mutations resulted in NRNI at positions 59 and 108. Finally, three mutations in the Pfdhfr gene resulted in the haplotype IRNI where amino acid changes occurred in position 51, 59 and 108. Amino acid positions 436, 437, 540, 581 and 613 in the Pfdhps gene were found to be very polymorphic. The wild type haplotype for Pfdhps is SAKAA ( $\mathrm{S}=$ serine, $\mathrm{A}=$ alanine and $\mathrm{K}=$ lysine). Single mutation at amino acid position 437 yielded one

Table 2 Pfcrt, Pfmdr1,Pfdhfr, Pfdhps and Kelch 13 genotyping success rate

\begin{tabular}{llll}
\hline Gene & $\begin{array}{l}\text { Number of genes successfully } \\
\text { genotyped }\end{array}$ & $\begin{array}{l}\text { Percentage of genes successfully } \\
\text { genotypes }\end{array}$ & $\begin{array}{l}\text { Range of absolute parasite count } \\
\text { (parasites/ } \mathrm{LL} \text { of blood) }\end{array}$ \\
\hline $\begin{array}{l}\text { P. falciparum multidrug resistance-1 } \\
\text { (Pfmdr1) }\end{array}$ & 74 & $81.3 \%$ & $773-4487$ \\
$\begin{array}{l}\text { P. falciparum chloroquine resistance } \\
\text { transporter (Pfcrt) }\end{array}$ & 77 & $84.6 \%$ & $851-4487$ \\
$\begin{array}{l}\text { P. falciparum dihydrofolate reductase } \\
\text { (Pfdhfr) }\end{array}$ & 79 & $86.8 \%$ & $609-4487$ \\
$\begin{array}{l}\text { P. falciparum dihydropteroate synthase } \\
\text { (Pfdhps) }\end{array}$ & 79 & $86.8 \%$ & $609-4487$ \\
$\begin{array}{l}\text { P. falciparum Kelch } 13 \text { propeller gene } \\
\text { (Kelch 13) }\end{array}$ & 84 & $92.3 \%$ & $382-4487$ \\
\hline
\end{tabular}


haplotype (SGKAA), double mutations at amino acid positions 436 and 437 yielded AGKAA haplotype. Three different triple mutation resulted in AGKAS (mutations at amino acid positions 436, 437 and 613), AGKSA (mutations at amino acid positions 436, 437 and 581) and FGKAS (mutations at amino acid positions 436, 437 and 613). One quadruple mutation resulted in AGKSS haplotype (mutations at amino acid positions 436, 437, 581 and 613) whilst one quintuple mutation resulted in AGESS haplotype (436, 437, 540, 581 and 613). Finally, five non-synonymous mutations were identified in the Kelch 13 gene; I543V, A578S, P615L, C580Y and A676S. The frequencies of each mutant haplotype is presented in Table 3. The overall frequency of mutant haplotype in Pfcrt, Pfmdr1, Pfdhfr, Pfdhps and Kelch 13 genes were 11.6, 29.7, 78.5, 87.3 and $16.6 \%$. There was a moderate relationship between parasitaemia and frequency of mutant alleles $(\mathrm{r}=0.42, p=0.034)$.

\section{Distribution of mutant alleles in the study sites}

Almost equal number of Pfcrt CVIET haplotype was observed in Ada East, Ashaiman and Ga South while mutant $P f m d r 1$ genes were almost equally distributed in the study areas. Also, majority of mutant Pfdhfr genes were seen in Ada East whereas, mutant Pfdhps genes were almost equally distributed. In Kelch 13 genes, four nonsynonymous SNPs were seen in Ada East and Ga South while two non-synonymous SNPs were seen in Ashaiman, Accra metropolis and Ga West (Fig. 1).

\section{Association of mutant haplotypes to demographic determinants}

Chi square analysis indicated no association between mutant haplotypes of Pfcrt, Pfmdr1, Pfdhfr, Pfdhps and Kelch 13 genes and demographic determinants. The distribution of mutant alleles was found to be comparable between all ages, gender and study sites.

\section{Discussion}

In malaria-endemic countries, asymptomatic carriers of malaria parasites have been shown to exist and blood donors are likely to harbour the malaria parasites, though asymptomatically, which could later be transfused to patients who may require transfusion. Many of blood transfusion users are pregnant women, immunocompromised patients such as children under 5 years, HIV, TB, cancer and malnourished patients. These groups of people are particularly at higher risk of transfusion-transmissible malaria (TTM) which may be compounded by possible anti-malaria drug resistance strains.

This study therefore describes putative anti-malaria drug resistance biomarkers in blood donors that were recruited in the Greater Accra region of Ghana. The
Table 3 Frequencies of $P$. falciparum mutant gene haplotypes identified in blood donors

\begin{tabular}{|c|c|c|}
\hline Gene & $\begin{array}{l}\text { Total number of mutant } \\
\text { haplotypes identified }\end{array}$ & $\begin{array}{l}\text { Percentage mutant } \\
\text { haplotypes identified }\end{array}$ \\
\hline \multicolumn{3}{|l|}{ Pfcrt $(n=77)$} \\
\hline CVIET & 9 & $11.6 \%$ \\
\hline \multicolumn{3}{|c|}{ Pfmdr1 $(n=74)$} \\
\hline NFD & 4 & $5.4 \%$ \\
\hline NYY & 4 & $5.4 \%$ \\
\hline YFN & 6 & $8.1 \%$ \\
\hline NFY & 8 & $10.8 \%$ \\
\hline \multicolumn{3}{|c|}{$\operatorname{Pfdhfr}(n=79)$} \\
\hline \multicolumn{3}{|c|}{ Single mutation } \\
\hline NRSI & 17 & $21.5 \%$ \\
\hline $\mathrm{NCNI}$ & 20 & $25.3 \%$ \\
\hline \multicolumn{3}{|c|}{$\begin{array}{l}\text { Double } \\
\text { mutation }\end{array}$} \\
\hline NRNI & 6 & $7.6 \%$ \\
\hline \multicolumn{3}{|c|}{$\begin{array}{l}\text { Triple } \\
\text { mutation }\end{array}$} \\
\hline IRNI & 19 & $24.0 \%$ \\
\hline \multicolumn{3}{|c|}{ Pfdhps $(n=79)$} \\
\hline \multicolumn{3}{|c|}{ Single mutation haplotype } \\
\hline SGKAA & 13 & $16.4 \%$ \\
\hline \multicolumn{3}{|c|}{ Double mutation haplotype } \\
\hline AGKAA & 12 & $15.2 \%$ \\
\hline \multicolumn{3}{|c|}{ Triple mutation haplotype } \\
\hline AGKAS & 11 & $13.9 \%$ \\
\hline AGKSA & 9 & $11.4 \%$ \\
\hline FGKAS & 5 & $6.3 \%$ \\
\hline \multicolumn{3}{|c|}{ Quadruple mutation haplotype } \\
\hline AGKSS & 5 & $6.3 \%$ \\
\hline \multicolumn{3}{|c|}{ Quintuple mutation haplotype } \\
\hline AGESS & 14 & $17.7 \%$ \\
\hline \multicolumn{3}{|c|}{ Kelch $13(n=84)$} \\
\hline \multicolumn{3}{|c|}{ Non-synonymous mutations } \\
\hline P615L & 4 & $4.8 \%$ \\
\hline A578S & 4 & $4.8 \%$ \\
\hline C580Y & 3 & $3.6 \%$ \\
\hline I543V & 2 & $2.4 \%$ \\
\hline A676S & 1 & $1.2 \%$ \\
\hline
\end{tabular}

genes of interest were Pfcrt, Pfmdr1, Pfdhps, Pfdhfr and Kelch 13 propeller genes. Allelic forms of these genes have been linked to anti-malaria drug resistance in several studies [15-18, 20].

In this study, the Pfcrt gene were found to contain three different amino acids at positions 74,75 and 76 resulting in M74I, N75E and K76T. Importantly, K76T 
mutation has been implicated in chloroquine resistance [29, 30]. In Ghana, incidence of K76T has been reported in several studies [22, 31, 32], however, K76T mutation may not complicate TTM, since chloroquine is no longer the drug of choice for the treatment of malaria. In Ghana, the drug of choice for management of uncomplicated malaria is artemisinin-based combination therapy (ACT). Non-synonymous mutations in Kelch 13 propeller gene is associated with artemisinin resistance especially in parasites causing infection in South-East Asia (SEA) [21].

In this study, five non-synonymous mutations $\mathrm{P} 615 \mathrm{~L}$, A578S, I543V, A676S and C580Y were identified in the Kelch 13 gene. The P615L mutation was detected in Pakistan [33]. Also, A676S has been identified in Africa and South-East Asia [34]. Again, S466N was identified in Peru [35] and subsequently in Colombia [36]. On the other hand, I543V allele has not been previously identified in any parasite strain. However, I543T, a very close allele to I543V, has been previously identified in SEA [34]. Outside SEA [34], C580Y has previously been identified in Africa specifically Cameroon [34] and Guyana in South America [37]. C580Y has been validated as artemisinin anti-malaria drug resistance allele $[20,34,38-$ 40], however, association of C580Y with anti-malaria drug resistance outside SEA has not been reported. Kelch 13 A578S allele, as was observed in this study, has also been previously detected in Ghanaian parasite isolates. In Ghana, A578S has been previously identified in three regions, Eastern, Bono (formerly Brong Ahafo) and in the Upper West Regions [23]. The A578S allele is two codons away from C580Y allele. Malaria endemic regions that have previously identified A578S, must enhance surveillance for C580Y allele. Matrevi et al. [23] have also detected C580V (very close allele of C580Y) in Central region of Ghana. Furthermore, Feng et al. [41] in 2013 also detected three isolates of C580Y SNP in Chinese migrant workers from Ghana. Two years later (in 2015), Huang et al. [42] also detected some cases of C580Y from Ghanaian immigrants to China. These reports highlight the fact that $\mathrm{C} 580 \mathrm{Y}$ allele is present in Africa and in Ghana in particular. It could, therefore, be concluded that C580Y allele could be an emerging Kelch 13 SNP in Ghana. It is therefore suggested that enhanced surveillance for C580Y in Ghana be implemented to unearth the actual burden of the SNP.

Mutations in the Pfmdr1 gene, have also been associated with chloroquine, amodiaquine, lumefantrine and mefloquine resistance [43, 44]. Amodiaquine, lumefantrine and mefloquine are artemisinin partner drugs. The most reported mutations in Pfmdr1 gene globally is N86Y, Y184F and N1246Y [16, 40, 42, 43]. In Ghana, these alleles have also been identified to be associated with reduced sensitivity of ACTs and other anti-malaria mono-therapies [45]. This study identified the double mutant, Y184F/D1246Y represented as NFY haplotype in $10.8 \%$ of the isolates while the triple mutant, YFN (N86Y/Y184F/D1246N) was observed in $8.1 \%$ of the isolates. Two single mutants, NFD (Y184F) and NYY (D1246Y) were identified in 5.4\% of the parasite isolates. Transmission of these haplotypes through blood transfusion, possibly will reduce the sensitivity of artemisinin partner drugs if infection is established. In Nigeria, N86Y and Y184F alleles have been associated with recurrent parasitaemia following ArtemetherLumefantrine therapy [46]. If even blood recipients are treated for malaria as suggested in other studies [47], they risk experiencing symptomatic infections due to the presence of N86Y and Y184F alleles.

In a study in the Volta region of Ghana, Kweku et al estimated malaria in pregnancy (MIP) to be $20.3 \%$ [48]. MIP is associated with severe maternal anaemia, low birth weight, increased perinatal mortality, pre-term birth, still birth and infant deaths [49, 50]. World Health Organization recommends intermittent preventive treatment of malaria in pregnancy (IPTp-MIP) with sulphadoxine-pyrimethamine (SP) to reduce the risk of poor MIP outcomes. With or without malaria parasitological testing, sulphadoxine-pyrimethamine for IPTp (IPTp-SP) is given to pregnant women. IPTp-SP is administered to either treat patient with parasites or provide a prophylactic effect to non-infected patients [51]. Mutations in two genes of P. falciparum, dihydropteroate synthase (Pfdhps) and dihydrofolate reductase (Pfdhfr) have been associated with resistance against sulfadoxine and pyrimethamine respectively. Accumulation of single point mutations in these genes have synergistic effect on reducing the efficacy of SP. The most important mutant biomarkers that increase the resistance of SP are combined triple Pfdhfr (N51I, C59R, S108N) and double Pfdhps (A437G, K540E) mutations resulting in quintuple mutation [52]. Analysis of genomic data obtained in this study indicated $24.0 \%$ triple mutations in the Pfdhfr gene (N51I, C59R, S108N resulting in IRNI haplotype) and $17.7 \%$ double mutations in Pfdhps gene (A437G, K540E resulting in AGESS haplotype). Further analysis revealed that 12 isolates representing $15.1 \%$ contained the quintuple mutations in the Pfdhfr and Pfdhps genes. This study reveal that quintuple mutations in the Pfdhfr and Pfdhps genes associated with infected donor blood could reduce the prophylactic efficacy of SP in pregnant women transfused with infected donor blood.

There is paucity of data with regards to previous findings on the prevalence and frequencies of anti-malaria drug resistant genes in blood donors in both endemic and non-endemic countries. However, several cases of anti-malaria drug resistant genes have been imported, by asymptomatic carriers, into non-endemic countries from 
endemic countries [41, 52-54]. Imported anti-drug resistant malaria is of public health concern since it has the potential to subvert global efforts to eradicate malaria. And also in regions with females Anopheles mosquitoes during transmission seasons, residents risk being transmitted with $P$. falciparum and more importantly, $P$. falciparum carrying drug resistant genes.

In a previous study [41], authors reported that imported $P$. falciparum malaria sharply increased in China, due to migrant workers who had returned from Ghana, a sub-Saharan malaria-endemic country. Of the 118 imported P. falciparum parasites that were evaluated, high prevalence of anti-malaria drug resistant gene polymorphisms, notably, N86Y, N86Y and D1246Y in Pfmdr1 genes and K76T in Pfcrt were reported. Again, four non-synonymous mutations in Kelch 13 gene were also identified (R539T, C580Y, C580F, D584V), one of which was identified in this study (C580Y). Findings from Feng et al. [41] and results obtained in this study confirm high prevalence of putative anti-malaria drug resistant biomarkers in asymptomatic infections in both Ghanaians and migrants from Ghana.

These findings raise concerns about the possible emergence of artemisinin resistance in Ghana. The impact of Pfmdr1 and Kelch 13 gene polymorphisms on Ghanaian P. falciparum parasite clearance times following ACT treatment need to be determined in further studies.

\section{Conclusion}

This study underscores high prevalence of malaria in Ghana which translated into $11.8 \%$ of asymptomatic infections in blood donors. For the first time, this study reports the prevalence of putative anti-malaria drug resistant markers in blood donors. Detection of C580Y Kelch 13 mutation, triple mutation haplotype, YFN, in Pfmdr1 gene and quadruple mutations in the Pfdhfr/Pfdhps genes (Pfdhfr: N51I, C59R, S108N resulting in IRNI haplotype and Pfdhps: A437G, K540E resulting in AGESS haplotype) could contribute to ACT treatment failure and reduced efficacy of sulphadoxine-pyrimethamine (SP) in transfusion recipients of malaria infected blood. All blood donors living in malaria endemic regions should be screened for malaria parasites to avert possible transmission of antimalaria drug resistant genes to blood recipients.

\section{Limitations of this study}

Inability to obtain $100 \%$ gene sequencing success rate could affect the relative frequencies and the distributions of the P. falciparum anti-malaria drug resistant gene alleles. However, results obtained in this study underscore the fact that anti-malaria drug resistant genes exist in Ghana.

\section{Abbreviations}

ACT: Artemisinin-based combination therapy; DBS: Dried blood spot; IPTpMIP: Intermittent preventive treatment of malaria in pregnancy; Kelch 13: Kelch 13 propeller domain on chromosome 13; MIP: Malaria in pregnancy; Pfcrt: P. falciparum chloroquine resistance transporter; Pfdhfr: $P$. falciparum dihydrofolate-reductase; Pfdhps: P. falciparum dihydropteroatesynthetase; PfHRP2: P. falciparum histidine rich protein 2; Pfmdr: P. falciparum multi-drug resistance; pLDH: Plasmodium lactate dehydrogenase; RDT: Rapid diagnostic test; SNPs: Single nucleotide polymorphisms; sWGA: Selective whole genome amplification; TTI: Transfusion transmissible infection; TTM: Transfusion transmissible malaria; AGKAA: Alanine-glycine-lysine-alaninealanine; AGKAS: Alanine-glycine-lysine-alanine-serine; AGKSA: Alanine-glycinelysine-serine-alanine; AGKSS: Alanine-glycine-lysine-serine-serine; CVIE

T: Cysteine-valine-isoleucine-glutamic acid-tyrosine; FGKAS: Phenylalanineglycine-lysine-alanine-serine; NCNI: Asparagine-cysteine-asparagine-isoleucine; NCSI: Asparagine-cysteine-serine-isoleucine; NFD: Asparagine-phenylalanineaspartic acid; NFY: Asparagine-phenylalanine-tyrosine; NRSI: Asparaginearginine-serine-isoleucine; NYY: Asparagine-tyrosine-tyrosine; SAKAA: Serinealanine-lysine-alanine-alanine; SGKAA: Serine-glycine-lysine-alanine-alanine; YFN: Tyrosine-phenylalanine-asparagine

\section{Acknowledgements}

Authors wish to acknowledge National Malaria Control Program for donation SD Rapid diagnostic test kits that were used in this study. We thank Malaria Genome Laboratory, Wellcome Sanger Institute, UK for sequencing the parasite isolates at no cost. Finally, appreciate the collaborative role of National Blood Service, Ghana.

\section{Authors' contributions}

EA, MGC and DOA conceptualized the study. EA, TR and CDT participated in the donor sample collection, preliminary processing of specimen and preparation and shipment of dry blood spots. EA, DOA, PA analysed sequenced data, MGC, TR and CDT drafted manuscript which was edited by EA, PA and DOA and was critically reviewed by KOD. All authors have read and approved the manuscript.

\section{Funding}

This study was funded from authors' own resources. No external funding was received. However, authors collaborated with Malaria Genome Laboratory, Wellcome Sanger Institute, Hinxton, United Kingdom to sequence Plasmodium isolates.

\section{Availability of data and materials}

Datasets generated and analysed in this study are available in the Harvard data verse repository (https://dataverse.harvard.edu/dataset.xhtml?persistentld=doi:1 0.7910/DVN/4ZZOEY). However, a request for the data can be obtained from the corresponding author on reasonable request.

\section{Ethics approval and consent to participate}

National Blood Service Ghana (NBSGRD/18903/01) and Ghana Health Service Ethical Review Committee (GHS-REC002/03/18) approved the study. Written informed consent was sought from each prospective blood donor which included the permission to publish the study outcome.

\section{Consent for publication}

Not applicable.

\section{Competing interests}

None to declare

\section{Author details}

${ }^{1}$ Department of Biomedical Sciences, School of Basic and Biomedical Sciences, University of Health and Allied Sciences, Ho, Volta Region, Ghana. ${ }^{2}$ Ghana Health Service, Accra, Ghana. ${ }^{3}$ New Juabeng Municipal Health Directorate, Koforidua, Ghana. ${ }^{4}$ Ghana Health Service, Municipal Health Directorate, Ga West Municipal, Amasaman, Ghana. ${ }^{5} \mathrm{Ga}$ North Municipal Health Directorate, Ofankor-Accra, Greater Accra Region, Ghana. ${ }^{6}$ School of Allied Health Sciences, Department of Biomedical Sciences, School of Allied Health Sciences, College of Health and Allied Science, University of Cape Coast, Cape Coast, Ghana. ${ }^{7}$ Malaria Genome Laboratory, Wellcome Sanger Institute, Hinxton, Cambridgeshire CB10 1SA, UK. 
Received: 6 January 2020 Accepted: 16 July 2020

Published online: 22 July 2020

\section{References}

1. Bruce-Chwatt LJ. Transfusion malaria revisited. Trop Dis Bull. 1982;79:827-40.

2. Owusu-Ofori AK, Betson M, Parry CM, Stothard R, Bates I. Transfusiontransmitted malaria in Ghana. Clin Infect Dis. 2013:56(12):1735-41.

3. Owusu-Ofori A, Gadzo D, Bates I. Transfusion-transmitted malaria: donor prevalence of parasitaemia and a survey of healthcare workers knowledge and practices in a district hospital in Ghana. Malar J. 2016;15(1):234.

4. Adusei KA, Owusu-Ofori A. Prevalence of Plasmodium parasitaemia in blood donors and a survey of the knowledge, attitude and practices of transfusion malaria among health workers in a hospital in Kumasi, Ghana. PLoS One. 2018;13(11):e0206303 https://doi.org/10.1371/journal.pone.0206303.

5. Mardani A, Keshavarz H, Pourfathollah AA, Maghsudlu M. Transfusion transmitted malaria in Iran: a narrative review article. Iran J Parasitol. 2016; 11(2):136-43.

6. Vareil MO, Tandonnet O, Chemoul A, Bogreau H, Saint-Léger M, Micheau M, Millet P, Koeck JL, Boyer A, Rogier C, Malvy D. Unusual transmission of Plasmodium falciparum, Bordeaux, France, 2009. Emerg Infect Dis. 2011;17: 248-50

7. Kitchen AD, Barbara JAJ, Hewit PE. Documented cases of post-transfusion malaria occurring in England: a review in relation to current and proposed donor-selection guidelines. Vox Sang. 2005;89:77-80.

8. Verra F, Angheben A, Martello E, Giorli G, Perandin F, Bisoffi Z. A systematic review of transfusion-transmitted malaria in non-endemic areas. Malar J. 2018;17(1):36. https://doi.org/10.1186/s12936-018-2181-0.

9. Mungai M, Tegtmeier G, Chamberland M, Parise M. Transfusion-transmitted malaria in the United States from 1963 through 1999. N Engl J Med. 2001; 344:1973-8.

10. Chattopadhyay R, Majam VF, Kumar S. Survival of Plasmodium falciparum in human blood during refrigeration. Transfusion. 2010. https://doi.org/10. 1111/j.1537-2995.2010.02872.x.

11. Seed CR, Kitchen A, Davis TM. The current status and potential role of laboratory testing to prevent transfusion-transmitted malaria. Transfus Med Rev. 2005;19:229-40.

12. Wylie BR. Transfusion transmitted infection: viral and exotic diseases. Anaesth Intensive Care. 1993;31:24-30

13. Manske M, Miotto O, Campino S, Auburn S, Almagro-Garcia J, Maslen G, et al. Analysis of Plasmodium falciparum diversity in natural infections by deep sequencing. Nature. 2012;487:375-9.

14. Ekland EH, Fidock DA. Advances in understanding the genetic basis of antimalarial drug resistance. Curr Opin Microbiol. 2007:10:363-70.

15. Fidock DA, Nomura T, Talley AK, Cooper RA, Dzekunov SM, Ferdig MT, et al. Mutations in the $P$ falciparum digestive vacuole transmembrane protein PfCRT and evidence for their role in chloroquine resistance. Mol Cell. 2000;6: $861-71$

16. Foote SJ, Kyle DE, Martin RK, Oduola AM, Forsyth K, Kemp DJ, et al. Several alleles of the multidrug-resistance gene are closely linked to chloroquine resistance in Plasmodium falciparum. Nature. 1990:345:255-8.

17. Wang P, Lee CS, Bayoumi R, Djimde A, Doumbo O, Swedberg G, et al. Resistance to antifolates in Plasmodium falciparum monitored by sequence analysis of dihydropteroate synthetase and dihydrofolate reductase alleles in a large number of field samples of diverse origins. Mol Biochem Parasitol. 1997:89:161-77.

18. Chusacultanachai S, Thiensathit P, Tarnchompoo B, Sirawaraporn W, Yuthavong Y. Novel antifolate resistant mutations of Plasmodium falciparum dihydrofolate reductase selected in Escherichia coli. Mol Biochem Parasitol. 2002;120:61-72

19. Jiang T, Chen J, Fu H, Kai W, Yao Y, Eyi JUM, et al. High prevalence of Pfdhfr-Pfdhps quadruple mutations associated with sulfadoxinepyrimethamine resistance in Plasmodium falciparum isolates from Bioko Island, Equatorial Guinea. Malar J. 2019;18:101. https://doi.org/10.1186/ s12936-019-2734-X

20. Ariey F, Witkowski B, Amaratunga C, Beghain J, Langlois AC, Khim N, et al. A molecular marker of artemisinin-resistant Plasmodium falciparum malaria Nature. 2014:505:50-5.

21. Hanboonkunupakarn B, White NJ. The threat of artemisinin resistant malaria in Southeast Asia. Travel Med Infect Dis. 2016;14(6):548-50. https://doi.org/ 10.1016/j.tmaid.2016.11.016
22. Dieng CC, Gonzalez L, Pestana K, Dhikrullahi SB, Amoah LE, Afrane YA, Lo E. Contrasting asymptomatic and drug resistance gene prevalence of Plasmodium falciparum in Ghana: implications on seasonal malaria chemoprevention. Genes (Basel). 2019;10(7):538. https://doi.org/10.3390/ genes 10070538

23. Matrevi SA, Opoku-Agyeman P, Quashie NB, Bruku S, Abuaku B, Koram KA, Fox A, Letizia A, Duah-Quashie NO. Plasmodium falciparum kelch propeller polymorphisms in clinical isolates from Ghana from 2007 to 2016. Antimicrob Agents Chemother. 2019;63:e00802-19 https://doi.org/10.1128/ AAC.00802-19.

24. Aninagyei E, Smith-Graham S, Boye A, Acheampong DO. Evaluating 18srRNA LAMP and selective whole genome amplification (sWGA) assay in detecting asymptomatic Plasmodium falciparum infections in blood donors. Malar J. 2019;18:214. https://doi.org/10.1186/s12936-019-2850-7.

25. WHO. Guidelines on assessing donor suitability for blood donation. World Health Organization 2012. http://www.who.int/iris/handle/10665/76724. Assessed on 7 August 2018.

26. WHO: Guidelines on drawing blood: Best practices in phlebotomy. 2010

27. WHO. Basic Malaria Microscopy: Part I Learner's guide, World Health Organization, Geneva, Switzerland, 1991

28. Oyola SO, Ariani CV, Hamilton WL, Kekre M, Amenga-Etego LN, Ghansah A, Rutledge GG, Redmond S, Manske M, Jyothi D, Jacob CG, Otto TD, Rockett K, Newbold Cl, Berriman M, Kwiatkowski DP. Whole genome sequencing of Plasmodium falciparum from dried blood spots using selective whole genome amplification. Malar J. 2016;15:597. https://doi.org/10.1186/s12936016-1641-7.

29. Ochong EO, van den Broek IV, Keus K, Nzila A. Short report: association between chloroquine and amodiaquine resistance and allelic variation in the Plasmodium falciparum multiple drug resistance 1 gene and the chloroquine resistance transporter gene in isolates from the upper Nile in southern Sudan. Am J Trop Med Hyg. 2003;69:84-187.

30. Basco LK, Ndounga M, Ngane VF, Soula G. Molecular epidemiology of malaria in Cameroon. XIV. Plasmodium falciparum chloroquine resistance transporter (PFCRT) gene sequences of isolates before and after chloroquine treatment. Am J Trop Med Hyg. 2002;67:392-5.

31. Ehrhardt S, Eggelte TA, Kaiser S, Adjei L, Burchard GD, Anemana SD, Bienzle U, Mockenhaupt FP. Large-scale surveillance of Plasmodium falciparum crt(K76T) in northern Ghana. Antimicrob Agents Chemother. 2007;51(9): 3407-9. https://doi.org/10.1128/AAC.00179-07.

32. Afoakwah R, Boampong JN, Egyir-Yawson A, Nwaefuna EK, Verner ON, Asare KK. High prevalence of PfCRT K76T mutation in Plasmodium falciparum isolates in Ghana. Acta Trop. 2014;136:32-6.

33. Yaqoob A, Khattak AA, Nadeem MF, Fatima H, Mbambo G, Ouattara A, Adams M, Zeeshan N, Takala-Harrison S. Prevalence of molecular markers of sulfadoxine-pyrimethamine and artemisinin resistance in Plasmodium falciparum from Pakistan. Malar J. 2018;17:471. https://doi.org/10.1186/ s12936-018-2620-y.

34. MalariaGEN Plasmodium falciparum Community Project. Genomic epidemiology of artemisinin resistant malaria. Elife. 2016;5:e08714. https:// doi.org/10.7554/eLife.08714.

35. Bacon DJ, McCollum AM, Griffing SM, Salas C, Soberon V, Santolalla M, Haley R, Tsukayama P, Lucas C, Escalante AA, Udhayakumar V. Dynamics of malaria drug resistance patterns in the Amazon basin region following changes in Peruvian national treatment policy for uncomplicated malaria. Antimicrob Agents Chemother. 2009;53(5):2042-51.

36. Aponte S, Guerra AP, Álvarez-Larrotta C, Bernala SD, Restrepo C, González C, Yasnot MF, Knudson-Ospinad A. Baseline in vivo, ex vivo and molecular responses of Plasmodium falciparum to artemether and lumefantrine in three endemic zones for malaria in Colombia. Trans R Soc Trop Med Hyg. 2017:1-10. https://doi.org/10.1093/trstmh/trx021.

37. Chenet SM, Akinyi Okoth S, Huber CS, et al. Independent emergence of the Plasmodium falciparum Kelch propeller domain mutant allele C580Y in Guyana. J Infect Dis. 2016;213(9):1472-5. https://doi.org/10.1093/infdis/ jiv752.

38. Straimer J, Gnadig NF, Witkowski B, Amaratunga C, Duru V, Ramadani AP, et al. Drug resistance. K13-propeller mutations confer artemisinin resistance in Plasmodium falciparum clinical isolates. Science. 2015; 347(6220):428 31 . doi: https://doi.org/10.1126/science.1260867.

39. Imwong M, Jindakhad T, Kunasol C, Sutawong K, Vejakama P, Dondorp AM. An outbreak of artemisinin resistant falciparum malaria in eastern Thailand. Sci Rep. 2015;5:17412. https://doi.org/10.1038/srep17412. 
40. Spring MD, Lin JT, Manning JE, Vanachayangkul P, Somethy S, Bun R, et al. Dihydroartemisinin-piperaquine failure associated with a triple mutant including kelch13 C580Y in Cambodia: an observational cohort study. Lancet Infect Dis. 2015;15:683-91.

41. Feng J, Li J, Yan H, Feng MY, Xia ZG. Evaluation of antimalarial resistance, marker polymorphism in returned migrant Workers in China. Antimicrob Agents Chemother. 2015;59:326-30. https://doi.org/10.1128/AAC.04144-14.

42. Huang F, Takala-Harrison S, Jacob CG, Liu H, Sun X, Yang H, et al. A single mutation in $\mathrm{K} 13$ predominates in southern China and is associated with delayed clearance of Plasmodium falciparum following artemisinin treatment. J Infect Dis. 2015;212:1629-35.

43. Berzosa P, Esteban-Cantos A, García L, González V, Navarro M, Fernández T, Romay-Barja M, Herrador Z, Rubio JM, Ncogo P, Santana-Morales M, Valladares B, Riloha M, Benito A. Profile of molecular mutations in pfdhfr, pfdhps, pfmdr1, and pfcrt genes of Plasmodium falciparum related to resistance to different anti-malarial drugs in the Bata District (Equatorial Guinea). Malar J. 2017;16:28. https://doi.org/10.1186/s12936-016-1672-0.

44. Venkatesan M, Gadalla NB, Stepniewska K, Dahal P, Nsanzabana C, Moriera C, et al. Polymorphisms in Plasmodium falciparum chloroquine resistance transporter and multidrug resistance 1 genes: parasite risk factors that affect treatment outcomes for $P$. falciparum malaria after artemether-lumefantrine and artesunate-amodiaquine. Am J Trop Med Hyg. 2014;91(4):833-43.

45. Kwansa-Bentum B, Ayi I, Suzuki T, Otchere J, Kumagai T, Anyan WK, et al. Plasmodium falciparum isolates from southern Ghana exhibit polymorphisms in the SERCA-type PFATPase6 though sensitive to artesunate in vitro. Malar J. 2011;10(187). https://doi.org/10.1186/1475-2875-10-187.

46. Ayogu EE, Ukwe CV, Mgbeahurike AC, Nna EO. Prevalence of Pfmdr1 86y and $184 \mathrm{f}$ alleles is associated with recurrent parasitemia following treatment of uncomplicated malaria with artemether-lumefantrine in Nigerian patients. J App Pharm Sci. 2016;6(04):015-21.

47. Rajab JA, Waithaka PM, Orinda DAO, Scott CS. Analysis of cost and effectiveness of pre-transfusion screening of donor blood and antimalarial prophylaxis for recipients. East Afr Med J. 2005;82(11):565-71.

48. Kweku M, Ofori M, Takramah W, Axame WK, Owusu R, Parbey P, Adjuik M, Tarkang E. Prevalence of malaria and anaemia among pregnant women attending antenatal Care Clinic in the Hohoe Municipality of Ghana. Int J Nurs Didactics. 2017;7 https://doi.org/10.15520/ijnd.2017.vol7.iss7.240.21-30

49. Desai M, ter Kuile FO, Nosten F, McGready R, Asamoa K, Brabin B, Newman $\mathrm{RD}$. Epidemiology and burden of malaria in pregnancy. Lancet Infect Dis. 2007;7:93-104.

50. Guyatt HL, Snow RW. Impact of malaria during pregnancy on low birth weight in sub-Saharan Africa. Clin Microbiol Rev. 2004;17:760.

51. World Health Organization: A strategic framework for malaria prevention and control during pregnancy in the African region. Brazzaville: Regional Office for Africa; 2004. AFR/MAL/04/01.

52. Happi $C T$, Gbotosho GO, Folarin OA, Akinboye DO, Yusuf BO, Ebong OO, et al. Polymorphisms in Plasmodium falciparum dhfr and dhps genes and age related in vivo sulfadoxine-pyrimethamine resistance in malaria infected patients from Nigeria. Acta Trop. 2005;95:183-93.

53. Sutherland CJ, Lansdell P, Sanders M, Muwanguzi J, van Schalkwyk DA, Kaur H, Nolder D, Tucker J, Bennett HM, Otto TD, Berriman M, Patel TA, Lynn R, Gkrania-Klotsas E, Chiodini PL. pfk13-independent treatment failure in four imported cases of Plasmodium falciparum malaria treated with artemetherlumefantrine in the United Kingdom. Antimicrob Agents Chemother. 2017; 61:e02382-16. https://doi.org/10.1128/AAC.02382-16.

54. Henriques G, Hallett RL, Beshir KB, Gadalla NB, Johnson RE, Burrow R, van Schalkwyk DA, Sawa P, Omar SA, Clark TG, Bousema T, Sutherland CJ. Directional selection at the pfmdr1, pfcrt, pfubp1, and pfap2mu loci of Plasmodium falciparum in Kenyan children treated with ACT. J Infect Dis. 2014;210:2001-8. https://doi.org/10.1093/infdis/jiu358.

\section{Publisher's Note}

Springer Nature remains neutral with regard to jurisdictional claims in published maps and institutional affiliations.

Ready to submit your research? Choose BMC and benefit from:

- fast, convenient online submission

- thorough peer review by experienced researchers in your field

- rapid publication on acceptance

- support for research data, including large and complex data types

- gold Open Access which fosters wider collaboration and increased citations

- maximum visibility for your research: over $100 \mathrm{M}$ website views per year

At BMC, research is always in progress.

Learn more biomedcentral.com/submissions 